
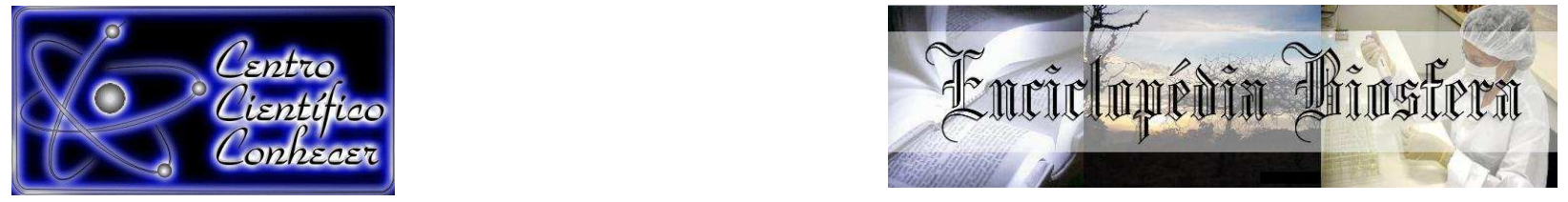

\title{
PERFIS DE ASSIMILAÇÃO DE CARBOIDRATOS DE UMA COMUNIDADE DE LEVEDURAS ASSOCIADAS AO CALDO DE CANA DE AÇÚCAR
}

\author{
Suzana Claudia Silveira Martins ${ }^{1}$, Renata Félix de Lima $^{2}$, Claudia Miranda Martins ${ }^{1}$ \\ 1 Professora Doutora do Departamento de Biologia da Universidade Federal do \\ Ceará (suzana220@gmail.com) Fortaleza-Brasil \\ 2 Mestre em Microbiologia pela Universidade Estadual do Rio de Janeiro \\ (refelix07@hotmail.com)
}

Recebido em: 03/10/2016 - Aprovado em: 21/11/2016 - Publicado em: 05/12/2016 DOI: 10.18677/EnciBio_2016B_120

\begin{abstract}
RESUMO
O preço do petróleo, o esgotamento das reservas naturais e a conscientização da preservação ambiental têm contribuído para a pesquisa de fontes alternativas de energia, como o bioetanol. No Brasil, entre as matérias-primas disponíveis para a produção desse combustível destaca-se o caldo de cana-de-açúcar. A levedura Saccharomyces cerevisiae é o agente biológico mais empregado nesse processo e, entre os carboidratos assimilados por este micro-organismo, estão glicose, sacarose, manose, galactose e maltose. No entanto, o interesse por cepas capazes de também assimilar outros açúcares, como a arabinose e a celobiose, é uma tendência atual para o aproveitamento do resíduo do bagaço da cana de açúcar visando à produção do etanol de segunda geração. Assim, o presente trabalho teve por objetivo avaliar o perfil de assimilação de diferentes carboidratos por cepas de leveduras isoladas do caldo de cana de uma indústria de fermentação alcoólica no nordeste brasileiro. Foram avaliadas 72 cepas previamente identificadas nos gêneros Candida (28), Pichia (25) e Saccharomyces (19). As cepas dos referidos gêneros apresentaram respectivamente 9, 7 e 5 perfis de assimilação. Nenhuma cepa de Saccharomyces foi capaz de assimilar arabinose e/ou celobiose, mas oito cepas $(47,3 \%)$ assimilaram os carboidratos glicose, maltose e sacarose, sugerindo a espécie Saccharomyces cerevisiae. Treze cepas do gênero Candida (46,4\%) e 11 Pichia (44,4\%) assimilaram todos os carboidratos inclusive, celobiose e arabionose e foram selecionadas como promissoras para bioconversão de hexoses e pentoses em etanol.
\end{abstract}

PALAVRAS-CHAVE: Assimilação, bioetanol, carboidratos.

\section{METABOLIC PROFILES OF THE COMMUNITY YEASTS ASSOCIATED WITH SUGAR CANE FROM THE ALCOHOLIC FERMENTATION PROCESS}

\footnotetext{
ABSTRACT

The price of oil, the depletion of natural resources and environmental conservation awareness has contributed to the search for alternative energy sources, such as bioethanol. In Brazil, among the available raw materials for the production of this fuel highlight the sugarcane juice. Saccharomyces cerevisiae is the most biological agent commonly used in this process, and among the carbohydrates assimilated by this ENCICLOPÉDIA BIOSFERA, Centro Científico Conhecer - Goiânia, v.13 n.24; p.1293 2016
} 
microorganism are glucose, sucrose, mannose, galactose and maltose. However, interest in strains able to assimilate also other sugars, such as arabinose and cellobiose is a current trend towards the utilization of waste bagasse from sugar cane aiming at the production of second generation ethanol. Thus, this study aimed to evaluate the assimilation profile of different carbohydrate for yeasts strains isolated of sugar cane juice from a fermentation industry in northeastern Brazil. Seventy two strains previously identified as Candida (28), Pichia (25) and Saccharomyces (19) were evaluated. Strains of these genera presented respectively, nine, seven and five carbohydrate assimilation profiles. No strain of Saccharomyces was able to assimilate arabinose and/or cellobiose but eight strains (47.3\%) assimilated glucose, maltose and sucrose, suggesting the species Saccharomyces cerevisiae. Thirteen strains of Candida (46.4\%) and 15 Pichia (44.4\%) assimilated all carbohydrates including cellobiose and arabionose and were selected as promising for bioconversion of hexoses and pentoses into ethanol.

KEYWORDS: assimilation, bioethanol, carbohydrates.

\section{INTRODUÇÃO}

O esgotamento das reservas de combustíveis fósseis aliado ao impacto ambiental da emissão de poluentes intensificou pesquisas por fontes renováveis de energia. Assim, a busca por combustíveis competitivos e ambientalmente corretos assumiram importância mundial (RAO et al., 2008) e, neste sentido, o bioetanol se apresenta como uma atrativa opção (ZABED et al., 2014).

No Brasil, o etanol é produzido a partir de caldo de cana de açúcar, que, dentre as matérias-primas utilizadas apresenta maior balanço energético (MACEDO, 2007). Referido substrato pode ser fermentado diretamente para a produção de etanol, denominado de primeira geração. Esse processo gera como resíduo uma biomassa celulósica que é considerado um recurso renovável para a produção de biocombustíveis de segunda geração. A hidrólise desse material celulolítico produz glicose, o dissacarídeo celobiose, além de pentoses, como a xilose e arabinose (KNOSHAUG et al., 2009). Segundo ALMEIDA et al. (2011), a utilização de arabinose é menos investigada que a xilose devido à menor abundância de arabinose na biomassa lignocelulósica. No entanto, a arabinose é o carboidrato mais abundante na parede celular de plantas e um dos principais constituintes da biomassa celulósica (KNOSHAUG et al., 2009).

Importante ressaltar, que a biomassa lignocelulosica é um substrato de grande valor biotecnológico e representa a maior fonte de matéria orgânica renovável, uma vez que é o maior componente estrutural de plantas lenhosas e não lenhosas. Esses resíduos são gerados através de práticas florestais e de agricultura, indústrias de papéis, madeira e outras agro-indústrias (HOWARD et al., 2003). A biomassa presente no bagaço da cana consiste de $40-55 \%$ de celulose, $25-50 \%$ de hemicelulose e $19-40 \%$ de lignina. A celulose e hemicelulose podem ser usadas em larga escala para a obtenção de biocombustíveis (MOURO, 2012).

A primeira etapa da conversão de um carboidrato em etanol é o transporte desse açúcar para o interior da célula, que por exigir proteínas transportadoras de membrana é específica para determinadas espécies de leveduras (YOUNG et al., 2010; SUBTIL \& BOLES, 2011). Importante destacar que segundo MOURO (2012), ainda são escassos estudos referentes ao transporte da celobiose por leveduras.

No Brasil, a levedura Saccharomyces cerevisiae é o principal microorganismo utilizado na produção de álcool combustível a partir da cana de açúcar. Os açúcares assimilados por este micro-organismo incluem a glicose, frutose, ENCICLOPÉDIA BIOSFERA, Centro Científico Conhecer - Goiânia, v.13 n.24; p.1294 
sacarose, manose, galactose e maltose (SÁ, 2012). No entanto referida levedura é incapaz de assimilar pentoses, como a arabinose presente em hidrolisados lignocelulósicos, ou o dissacarideo celobiose encontrado nos hidrolisados de celulose (KHALORINIA et al., 2014). Assim, a pesquisa por cepas de leveduras capazes de assimilar referidos carboidratos é um desafio para a produção de etanol de segunda geração (MARTINI, 2014). KNOSHAUG et al. (2009) e SUBTIL \& BOLES (2011) sugerem que os genes transportadores de micro-organismos assimiladores de pentoses podem ser isolados e inseridos em cepas de Saccharomyces cerevisiae. Para ZUROFF et al. (2013) consórcios de leveduras celulolíticas e etanologênicas poderiam ser uma alternativa atraente para 0 aproveitamento de resíduos celulósicos na produção de bioetanol. YADAV et al. (2011) registraram o experimento realizado com a cepa Pichia stipitis assimiladora de arabinose consorciada com uma cepa de Saccharomyces cerevisiae.

Segundo MARTINI (2014), a produção eficiente de etanol a partir de substratos hemicelulósicos exige que a levedura tenha a capacidade de utilizar não apenas a glicose, mas também os outros açúcares, como a arabinose. Assim, a incapacidade de assimilação especificamente da arabinose e da celobiose pela Saccharomyces cerevisiae (YOUNG et al., 2010; SUBTIL \& BOLES, 2011) é um fator limitante para o uso da biomassa celulósica na produção de etanol (BECKER \& BOLES, 2003; RICHARD et al., 2003; KARHUMAA et al., 2006).

Entre as leveduras que assimilam pentoses, MARTINI (2014) destaca espécies dos gêneros, Pichia, Candida, Kluyveromyces, Brettanomyces/Dekkera, Debaryomyces e Schizosaccharomyces. Diante do exposto, e tendo em vista que a absorção simultânea de hexoses e pentoses é um pré-requisito para o sucesso da fermentação da biomassa lignocelulósica em etanol, o presente estudo teve por objetivo avaliar o perfil metabólico para assimilação de carboidratos, com destaque para a arabinose e celobiose, em leveduras isoladas do caldo de cana, matéria prima de uma indústria de fermentação alcoólica do nordeste brasileiro.

\section{Leveduras}

\section{MATERIAL E MÉTODOS}

Foram recuperadas 72 cepas de leveduras previamente isoladas de amostras de caldo de cana, de uma indústria de fermentação alcoólica do Estado do Ceará. Essas cepas foram caracterizadas e identificadas como pertencentes aos gêneros Saccharomyces (19), Pichia (25) e Candida (28) (MARTINS et al., 2015). Atualmente estão mantidas na Coleção de Culturas do Laboratório de Microbiologia Ambiental (LAMAB) do Departamento de Biologia da Universidade Federal do Ceará (UFC), em Ágar Sabouraud camada alta cobertas com óleo mineral, a temperatura de $4 \stackrel{\circ}{\circ}$.

\section{Assimilação de carboidratos - Auxanograma}

Os carboidratos, glicose, maltose, sacarose, manose, celobiose e arabinose foram adicionados ao meio de cultura com a seguinte composição (sulfato de amônio $5 \mathrm{~g}$, fosfato monopotássico $1 \mathrm{~g}$, sulfato de magnésio $0,5 \mathrm{~g}$, ágar $15 \mathrm{~g}$, água destilada q.s.p. $100 \mathrm{~mL}$, autoclavado a $115^{\circ} \mathrm{C}$ por $15 \mathrm{~min}$. Alíquotas de $40 \mathrm{~mL}$ do meio fundido foram distribuídas em placas de Petri com dois $\mathrm{mL}$ das suspensões das cepas de leveduras. Com a ponta de uma espátula foram adicionados os distintos carboidratos em diferentes pontos. As placas foram incubadas a $25{ }^{\circ} \mathrm{C}$ durante sete dias.

Os perfis de assimilação de carboidratos das leveduras foram construídos a partir de dados da interação binária (0 para as cepas que não apresentaram zona de ENCICLOPÉDIA BIOSFERA, Centro Científico Conhecer - Goiânia, v.13 n.24; p.1295 2016 
crescimento macroscópico em torno do local onde foi adicionado o açúcar. e 1 para as que apresentaram referida zona de crescimento). Para isso foi usado o Excel (Microsoft Office 2007) para Análise Gráfica de Dados. Glicose foi usada como controle positivo e o meio base sem o carboidrato como controle negativo (SOUZA et al., 2015).

\section{RESULTADOS E DISCUSSÃO}

As Figuras 1, 2 e 3 apresentam os perfis de assimilação de carboidratos das cepas de leveduras dos gêneros Saccaharomyces, Candida e Pichia isoladas de amostras de caldo de cana.

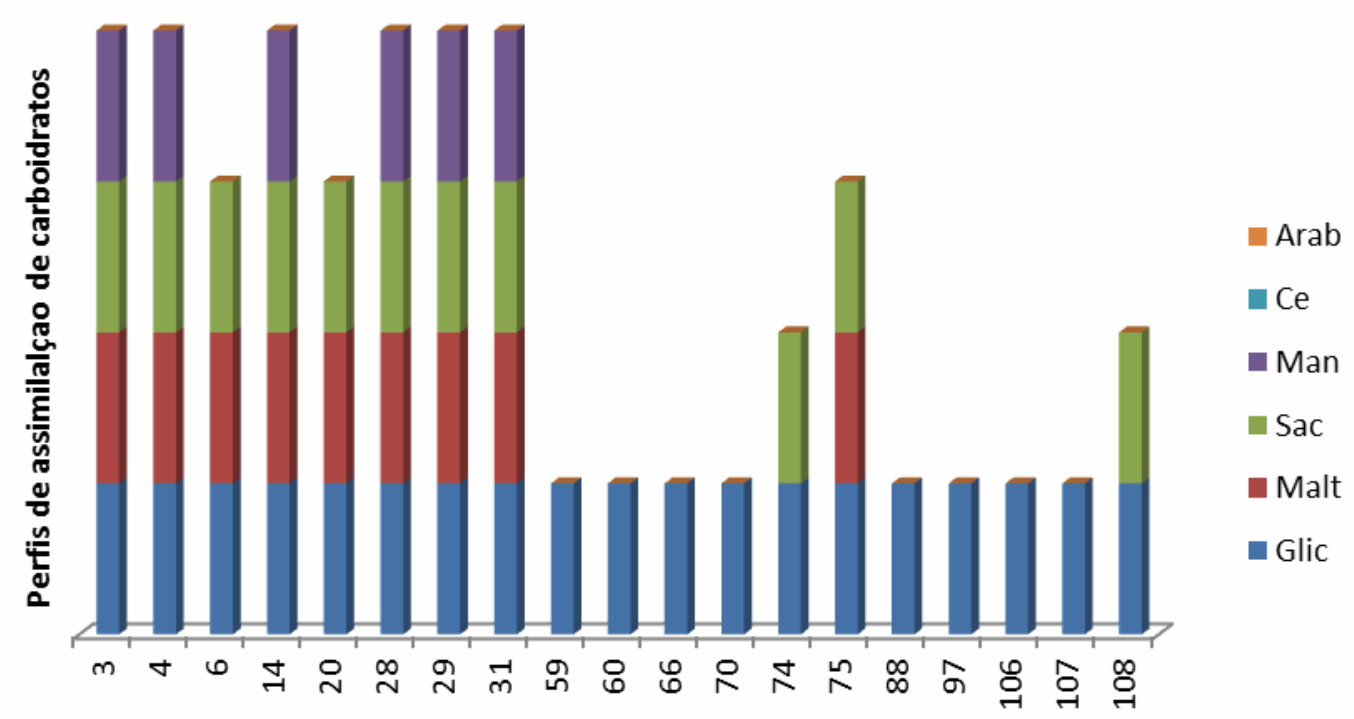

Cepas de leveduras do gênero Saccharomyces isoladas de caldo de cana

FIGURA 1 Perfis de assimilação de carboidratos das leveduras do gênero Saccharomyces isoladas do caldo de cana

Todas as cepas de leveduras do gênero Saccharomyces assimilaram a glicose, mas foram incapazes de assimilar a pentose arabinose e/ou o dissacarídeo celobiose. COSTA et al. (2013) avaliando 31 cepas de Saccharomyces cerevisiae do Banco de Micro-organismos da Fermentec, também não encontraram nenhuma cepa capaz de utilizar a celobiose e/ou arabinose. Essa limitação, confirmada por ZABED et al. (2014) e CASSA-BARBOSA (2015) ressalta a importância da pesquisa por cepas de leveduras com potencial para assimilação dos referidos carboidratos visando o aproveitamento de frações celulósicas para produção de bioetanol de segunda geração (LENNARTSSON et al., 2014).

As cepas 59,60, 66, 70, 88, 97, 106, 107, assimilaram somente a glicose. Esses resultados são comuns às espécies Saccharomyces dairenensis (OHARA et al., 2012), Saccharomyces rosinii (ALI \& KHAN, 2014), Saccharomyces transvaalensis (OHARA et al., 2013) e Saccharomyces unisporus (BHATTACHARYA et al., 2013).

Nove cepas de leveduras do gênero Saccharomyces, $(3,4,6,14,20,28,29$, 31 e 75 ) representando $47,3 \%$ da população analisada, assimilaram pelo menos os carboidratos glicose, maltose e sacarose, perfil sugestivo da espécie Saccharomyces cerevisiae. As cepas 74 e 108 (10,5\%) assimilaram glicose e 
sacarose e segundo ALI \& KHAN. (2014) a espécie Saccharomyces exiguus apresenta essas características.

Em estudos para a seleção de cepas de Saccharomyces cerevisiae que apresentem melhor desempenho na produção de etanol a partir da hidrólise intracelular da sacarose do caldo de cana, WEUSTHUIS et al. (1993) ressaltaram a importância de cepas capazes de sintetizar permeases específicas para captar de forma direta a sacarose. Assim, as cepas (3, 4, 6, 14, 20, 28, 29, 31, 74, 75 e 108) podem ser consideradas promissoras para a produção de etanol de primeira geração a partir do caldo de cana.

$\mathrm{Na}$ Figura 2 estão os perfis assimilativos das cepas de leveduras do gênero Candida avaliadas neste estudo.

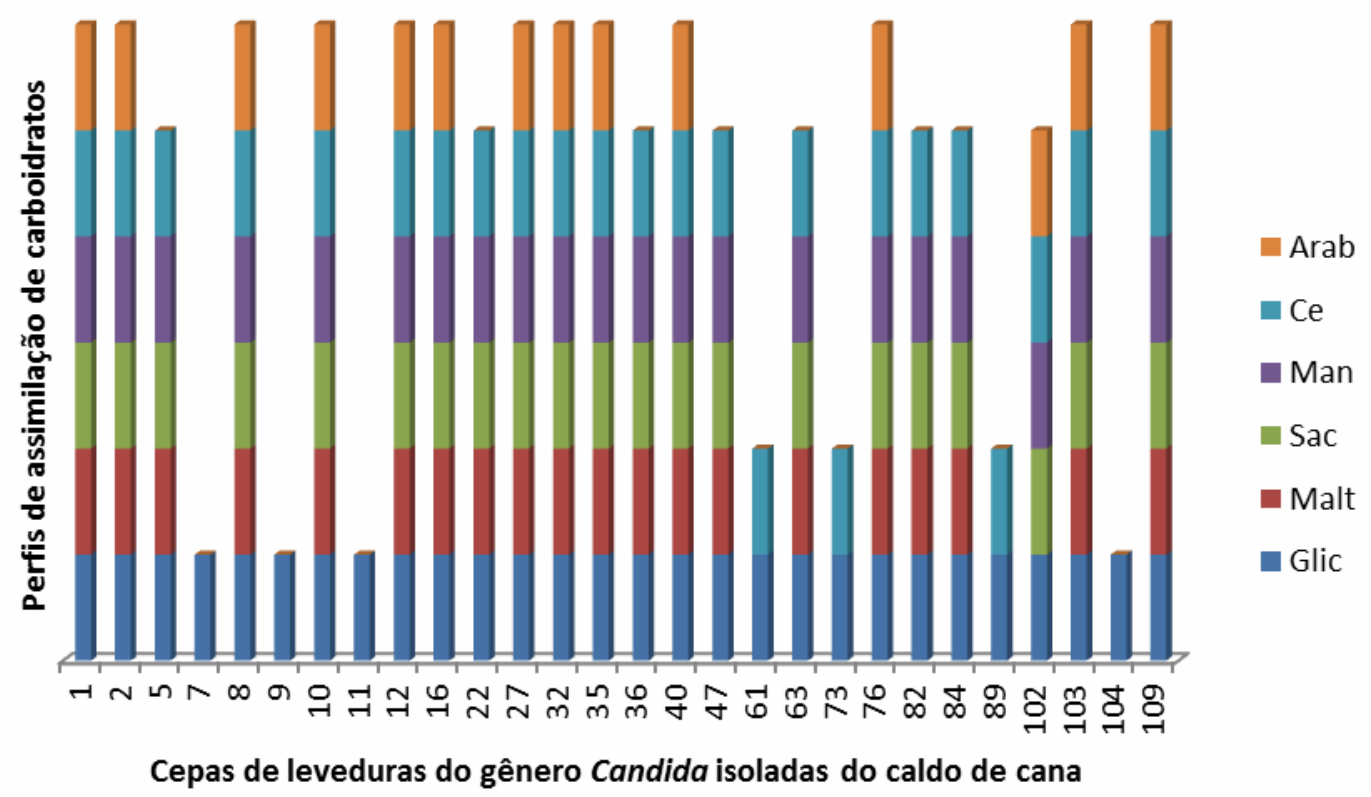

FIGURA 2 Perfis de assimilação de carboidratos das leveduras do gênero Candida isoladas do caldo de cana.

Constata-se que $50 \%$ das cepas de leveduras do gênero Candida (1, 2, 8, 10 , $12,16,27,32,35,40,76,102,103$ e 109) foram capazes de assimilar celobiose e arabinose. Observa-se também que as cepas 5, 22, 36, 47, 61, 63, 73, 82, 84 e 89 $(35,7 \%)$, embora tenham sido incapazes de assimilar arabinose apresentaram enzimas para absorção da celobiose. SANTOS et al. (2010) trabalhando com leveduras isoladas de ecossistemas da Mata Atlântica no Brasil, identificaram as espécies Candida lignicola e Candida coipomoensis como assimiladoras de celobiose.

CASSA-BARBOSA et al. (2015) avaliando 231 colônias de leveduras isoladas da região Amazônica constataram que 125 foram capazes de assimilar pentoses entre elas, a arabinose como fonte de carbono. Entre as espécies identificadas os autores destacaram as espécies Candida lignohabitans e Candida etanolica. CHANDEL et al. (2011) descreveram a Candida sheatae como uma espécie assimiladora natural de pentoses, enquanto KHALORINIA et al. (2014) revelaram que as cepas Candida tropicalis Y-27405, Candida intermedia MTCC-1404 e Candida tropicalis Y-1552, foram capazes assimilar pentoses e a $C$. intermedia MTCC-1404 foi a que apresentou melhor desempenho. WANNAWILAI \& 
SIRISANSANEEYAKUL (2015) em estudo semelhante registraram a cepa Candida magnoliae TISTR 5663 como promissora para absorção de pentoses.

Os perfis de assimilação de carboidratos apresentados pelas cepas do gênero Candida oriundas de amostras de caldo de cana revelaram cepas promissoras para atuar em consórcio com cepas de Saccharomyces cerevisiae na fermentação de material celulósico.

A Figura 3 apresenta o perfil assimilativo de carboidratos da população de leveduras do gênero Pichia oriundas de amostras de caldo de cana.

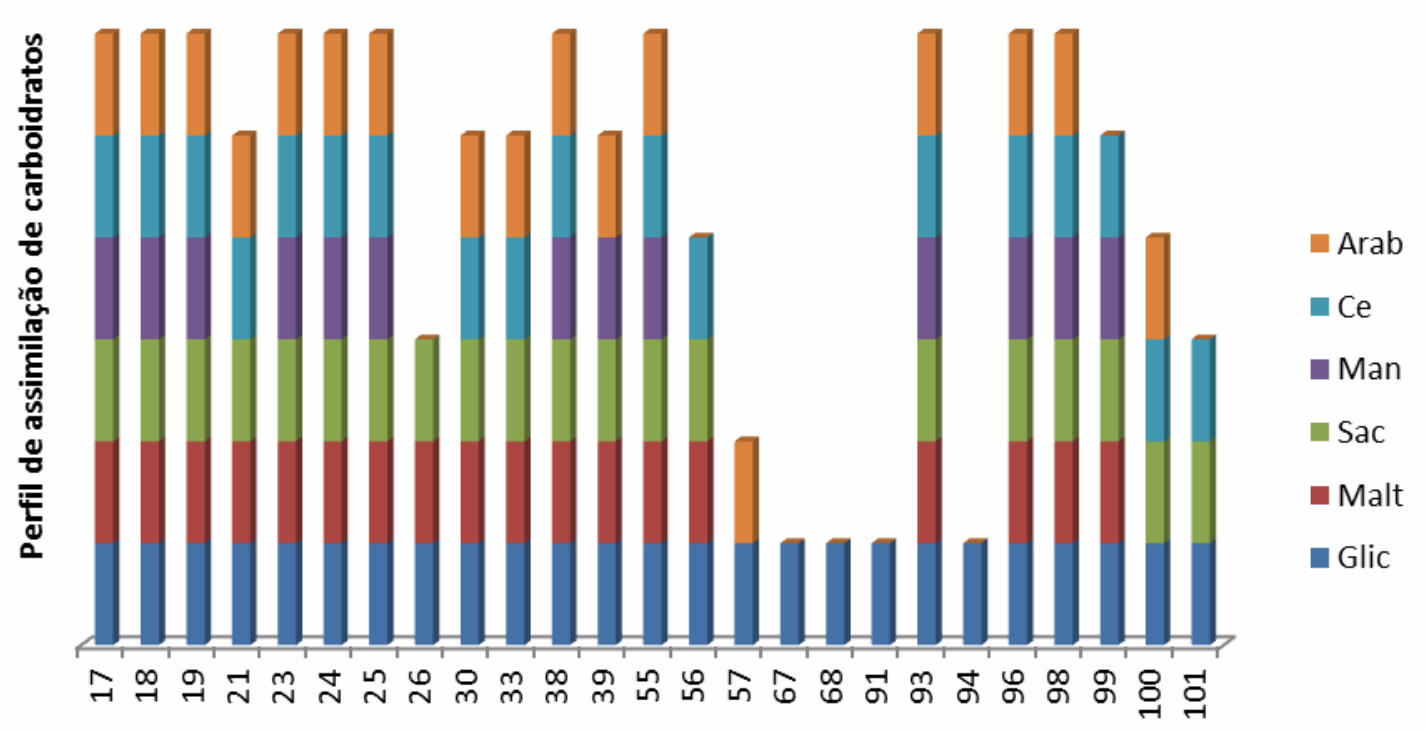

Cepas de leveduras do gênero Pichia isoladas de caldo de cana

FIGURA 3 Perfis de assimilação de carboidratos das leveduras do gênero Pichia isoladas do caldo de cana.

O gênero Pichia apresentou o percentual mais representativo de cepas assimiladoras de celobiose e arabinose. Como pode ser observado na Figura 3 , as cepas $17,18,19,21,23,24,25,28,30,33,55,57,93,94,96,98,99$ e 100 (72\%) assimilaram a celobiose e a arabinose. Ressalte-se ainda que a cepa 57 assimilou somente arabinose e a 101 apenas celobiose. Importante destacar que $44 \%$ das cepas do gênero Pichia $(17,18,19,23,24,25,38,55,93,96$ e 98) assimilaram todos os carboidratos avaliados.

A assimilação de carboidratos pela célula microbiana está relacionada a sistemas específicos localizados na membrana citoplasmática (SUBTIL \& BOLES, 2011). Em experimentos para detecção do sistema de transporte para arabinose em 165 cepas de leveduras não Saccharomyces KNOSHAUG et al. (2009) registraram que as espécies Pichia guilliermondii, Pichia methanolica e Pichia scolyti foram portadoras dos referidos sistemas. CHANDEL et al. (2011) em trabalho com leveduras isoladas de material celulósico registraram a espécie Pichia stiptis capaz de assimilar arabinose, mas não celobiose. Esse perfil foi detectado nas cepas 26, 39 e 57. A cepa 25 foi identificada por MARTINS et al. (2015) como Pichia anomala e classificada como capaz de assimilar todos carboidratos avaliados, inclusive a celobiose e arabinose. Esse resultado está de acordo com LODDER (1971). ZHA et al. (2013) identificaram uma cepa de Pichia anomala como capaz de assimilar pentoses e promissora para produção de bioetanol a partir de material celulósico. A levedura Pichia pastoris é muito estudada por seu potencial na produção de ENCICLOPÉDIA BIOSFERA, Centro Científico Conhecer - Goiânia, v.13 n.24; p.1298 2016 
bioetanol por ser capaz de assimilar pentoses presentes em biomassa celulósica (SHIN et al., 2015).

\section{CONCLUSÕES}

Os resultados do presente estudo indicam o potencial de cepas de leveduras dos gêneros Pichia e Candida, para aplicação consorciada com Saccharomyces cerevisiae ou para inserção dos genes responsáveis pela assimilação de arabinose e/ou celobiose em cepas de Saccharomyces cerevisiae a serem utilizadas para produção de bioetanol.

\section{REFERÊNCIAS}

ALMEIDA, J.R.; RUNQUIST, D.; SÀNCHEZ I NOGUÉ, V.; LIDÉN, G.; GORWAGRAUSLUND, M.F. Stress-related challenges in pentose fermentation to ethanol by the yeast Saccharomyces cerevisiae. Biotechnology Journal, v.6, n. 3, p. 286-299, 2011. Disponível em: < http://dx.doi.org/10.1002/biot.201000301>. doi: 10.1002/biot.201000301

ALI, M.N.; KHAN, M.M. Screening, identification and characterization of alcohol tolerant potential bioethanol producing yeasts. Current Research in Microbiology and Biotechnology, v. 2, n. 1, p. 316-324, 2014. Disponível em: < http://crmb.aizeonpublishers.net/content/2014/1/crmb>.

BECKER, J.; BOLES, E. A modified Saccharomyces cerevisiae strain that consumes I-arabinose and produces ethanol. Applied and Environental Microbiology, v. 69, n.7 p.4144-4150, 2003. Disponível em: < http://aem.asm.org/content/69/7/414>. doi: 10.1128/AEM. 69.7.4144-4150.2003.

BHATTACHARYA, I.; YAN, S.; YADAV, J.S.S.; TYAGI, R.D.; SURAMPALLI, R.Y. Saccharomyces unisporus: Biotechnological potential and present status. Comprehensive Reviews in Food Science and Food Safety, v. 12, n. 4, p. 353363, 2013. Disponível em: < http://www.oalib.com/references/5813737> doi: 10.1111/1541-4337.12016.

CASSA-BARBOSA, L.A.; PROCÓPIO, R.E.L.; MATOS, I.T.S.R.; FILHO, S.A. Isolation and characterization of yeasts capable of efficient utilization of hemicellulosic hydrolyzate as the carbon source. Genetics and Molecular Research, v.14, n. 3, p.11605-11612, 2015. Disponível em: http://www.ncbi.nlm.nih.gov/pubmed/26436401> doi:http://dx.doi.org/10.4238/2015.September.28.12

COSTA, V.M.; LOPES, M.L.; PAULILO, S.C.L.; SOUZA, S.C.; AMORIM, H.V. Cinética de crescimento de leveduras Saccharomyces cerevisiae em diferentes fontes de carbono. 27ํㅡㄹ Congresso Brasileiro de Microbiologia. Resumos. 2013. Disponível em: http://www.sbmicrobiologia.org.br/cd27cbm/resumos/R0839-1.htm

CHANDEL A.K.; SINGH, O.V.; RAO, L.V.; CHANDRASEKHAR, G.; NARASU M.L. Bioconversion of novel substrate Saccharum spontaneum, a weedy material, into ethanol by Pichia stipitis NCIM3498. Bioresource Technology, v. 102, n. 2, p.17091714, 2011. Disponível em: < http://dx.doi.org/10.1016/j.biortech.2010.08.016>. doi: 10.1016/j.biortech.2010.08.016 
HOWARD, R.L.; ABOTSI, E; JANSEN VAN RENSBURG, E.L.; HOWARD, S. Lignocellulose biotechnology: issues of bioconversion and enzyme production. African Journal of Biotechnology, v. 2, n. 12, p. 602-619, 2003. Disponível em: < http://www.academicjournals.org/journal/AJB/article-full-text-pdf/C18EA4B11309>

KALHORINIA, S.; EOLI J.K.; RAO, V. Screening and parameters optimization of pentose fermenting yeasts for etanol production using simulated media. Biosciences Biotechnology Research Asia. v. 11, n. 2, 641-648, 2014. Disponível em: < http://www.biotech-asia.org/vol11 no2/screening-and-parameters-optimization-ofpentose-fermenting-yeasts-for-ethanol-production-using-simulated-media/>. $\quad$ doi: http://dx.doi.org/10.13005/bbra/1317.

KARHUMAA, K.; WIEDEMANN, B.; HAHN-HÄGERDAL, B.; BOLES, E.; GORWAGRAUSLUND, M.F. Co-utilization of L-arabinose and D-xylose by laboratory and industrial Saccharomyces cerevisiae strains. Microbial Cell Factories, v. 5, n. 18, p. 1-11, 2006. <Disponível em: http://www.ncbi.nlm.nih.gov/pubmed/16606456>. doi: 10.1186/1475-2859-5-18.

KNOSHAUG, E.P.; FRANDEN, M.A.; STAMBUK, B.U.; ZHANG, M. Utilization and transport of L-arabinose by non-Saccharomyces yeasts. Arjun Singh Cellulose v.16, p. 729-741, 2009. Disponível em: http://link.springer.com/article/10.1007/s10570-009-9319-8 >. doi: 10.1007/s10570009-9.

LODDER, J. The yeasts. A taxonomic study. 1385 p. 1971.

LENNARTSSON, P.R.; ERLANDSSON, P.; TAHERZADEH, M.J. Integration of the first and second generation bioethanol processes and the importance of by-products. Bioresource Technology, v. 165, p. 3-8, 2014. Disponível em:< http://dx.doi.org/10.1016/j.biortech.2014.01.127> doi: 10.1016/j.biortech.2014.01.127.

MACEDO, I. Situação atual e perspectivas do etanol. Estudos Avançados, v. 21, n. 59, p. 157-165, 2007. $\quad$ Disponível $\quad$ em:< http://www.scielo.br/pdf/ea/v21n59/a11v2159.pdf>.

MARTINS, S.C.S; LIMA, R.F.; MARTINS, C.M. Isolamento e caracterização de leveduras de caldo de cana de uma indústria de fermentação alcoólica no nordeste brasileiro. Enciclopédia Biosfera, v. 11, n. 22, p. 3019-3035, 2015. Disponível em: < DOI: http://dx.doi.org/10.18677/Enciclopedia_Biosfera_2015_020>. doi: 10.18677/Enciclopedia_Biosfera_2015_020.

MARTINI, C. Isolamento, identificação e caracterização de linhagem de levedura quanto ao crescimento e fermentação utilizando meios sintéticos com pentoses e hidrolisado de bagaço de cana-de-açúcar. $121 \mathrm{f}$. Tese (Doutorado em Microbiologia Aplicada), Universidade Estadual de São Paulo, 2014. Disponível em: http://repositorio.unesp.br/handle/11449/110412 
MOURO, A. Fermentação de xilose e celobiose por leveduras isoladas da biodiversidade brasileira. 72 f. Dissertação (Mestrado em Biotecnologia)Universidade Federal de Santa Catarina, 2012. Disponivel em: < https://repositorio.ufsc.br/handle/123456789/100622>

OHARA, S.; FUKUSHIMA, Y.; SUGIMOTO, A.; TERAJIMA, Y.; ISHIDA, T.; SAKODA, A. Rethinking the cane sugar mill by using selective fermentation of reducing sugars by Saccharomyces dairenensis, prior to sugar crystallization. Biomass and Bioenergy, v. 42, p. 78-85, 2012. Disponível em: < http://dx.doi.org/10.1016/j.biombioe.2012.03.024.>doi: 10.1016/j.biombioe.2012.03.024.

OHARA, S.; KATAO, T.; FUKUSHIMA, Y.; SAKODA, A. Selective ethanol production from reducing sugars in a saccharide mixture. Journal of Bioscience and Bioengineering, v. 115, n. 5; p. 540-543, 2013. Diponível em: < http://dx.doi.org/10.1016/j.jbiosc.2012.11.010. > doi: 10.1016/j.jbiosc.2012.11.010

RAO, R. S.; BHADRA, B.; SHIVAJI, S. Isolation and characterization of ethanolproducing yeasts from fruits and tree barks. Letters in Applied Microbiology, v. 47, p. 19-24, 2008. Disponível em:< http://www.ncbi.nlm.nih.gov/pubmed/18498317>. doi:10.1111/j.1472-765X.2008.02380.x.

RICHARD, P.; VERHO, R.; PUTKONEN, M.; LONDESBOROUGH, J.; PENTTILA, M. Production of ethanol form L-arabinose by Saccharomyces cerevisiae containing a fungal L-arabinose pathway. FEMS Yeast Research, v. 3, n.2, p. 185-189, 2003. Disponível em: http://onlinelibrary.wiley.com/doi/10.1016/S1567-1356(02)001848/pdf. doi :10.1016/S1567-1356(02)00184-8.

SÁ, C.B.C. Caracterização de linhagens de Saccharomyces cerevisiae e Zymomonas mobilis para aplicação na produção de bioetanol. 92 p. Dissertação (Mestrado em Biotecnologia Industrial), Universidade Federal de Pernambuco, 2012. Disponível em: < http://repositorio.ufpe.br:8080/xmlui/handle/123456789/1222>.

SANTOS, R.O. Leveduras fermentadoras de pentoses produtoras de xilanases e celulases associadas ao bagaço da cana de açúcar em decomposição. $115 \mathrm{p}$. Dissertação (Mestrado em Microbiologia), Universidade Federal de Minas Gerais. 2010. Disponível em: http://www.bibliotecadigital.ufmg.br/dspace/handle/1843/ICBD8EXP34.

SHIN, S. K.; HYEON, J. E.; KIM, Y. I.; KANG, D. H.; KIM, S. W.; PARK, C.; HAN, S. $\mathrm{O}$. Enhanced hydrolysis of lignocellulosic biomass: Bi-functional enzyme complexes expressed in Pichia pastoris improve bioethanol production from Miscanthus sinensis. Biotechnology Journal, 10, n.12, p. 1912-1919, 2015. Disponível em: http://www.ncbi.nlm.nih.gov/pubmed/26479167. doi: 10.1002/biot.201500081.

SOUZA, M. N.; ORTIZ, S. O.; MELLO, M. M.; OLIVEIRA, F. M.; SEVERO, L. C.; GOEBEL, C. S. Comparison between four usual methods of identification of Candida species. Revista do Instituto de Medicina Tropical de São Paulo, v.57, n.4, p.281287, 2015. Disponível em:< http://dx.doi.org/10.1590/S0036-46652015000400002> doi: 10.1590/S0036-46652015000400002. 
SUBTIL, T.; BOLES, E. Improving L-arabinose utilization of pentose fermenting Saccharomyces cerevisiae cells by heterologous expression of $\mathrm{L}$-arabinose transporting sugar transporters. Biotechnology for Biofuels, v.4, n. 38, p. 1-10, 2011. Disponível em: < http://www.ncbi.nlm.nih.gov/pubmed/21992610> doi: 10.1186/1754-6834-4-38.

YADAV, K. S.; NASEERUDDIN, S., SAI, G. P.; SATEESH, L.; VENKATESWAR, L. $R$. Bioethanol fermentation of concentrated rice straw hydrolysate using co-culture of Saccharomyces cerevisiae and Pichia stipitis. Bioresource Technology, v.102, n.11, p.6473-6478, 2011. Disponível em: <http://dx.doi.org/10.1016/j.biortech.2011.03.019>. doi: 10.1016/j.biortech.2011.03.019.

YOUNG, E.; LEE, SUN-MI; ALPEER, H. Optimizing pentose utilization in yeast: the need for novel tools and approaches. Biotechnology for Biofuels, v. 3, n. 24, p. 112, 2010. Disponível em: < http://www.ncbi.nlm.nih.gov/pubmed/2108092 > . doi: 10.1186/1754-6834-3-2.

WEUSTHUIS, R.A.; ADAMS, H.; SCHEFFERS, W.A.; VAN DIJKEN, V.P. Energetics and kinetics of maltose transport in Saccharomyces cerevisiae: a continuous culture study. Applied and Environmental Microbiology, v. 59, n.9 p.3102-3109, 1993. Disponível em: < http://www.ncbi.nlm.nih.gov/pubmed/8215379>.

WANNAWILAI, S.; SIRISANSANEEYAKUL, S. Economical production of xylitol from Candida magnolia TISTR 5663 using sugarcane bagasse hydrolysate. Kasetsart Journal, v. 49, p. 583-596, 2015. Disponível em: < https://research.rdi.ku.ac.th/world/showltem.phpitemID=189099>.

ZABED, H.; FARUQ, G.; SAHU,J.N.; AZIRUN,M.S.; HASHIM, R.; BOYCE, A.N. Bioethanol Production from Fermentable Sugar Juice. The Scientific World Journal, v. 2014, p. 1-11. 2014. Disponível em: < http://dx.doi.org/10.1155/2014/957102 >. doi: 10.1155/2014/957102.

ZHA, Y.; ABEER, H. H.; TOBOLA, F.; SEDEE, N.; HAVEKES, M.; PUNT, P.J. Pichia anomala 29X: a resistant strain for lignocellulosic biomass hydrolysate fermentation. FEMS Yeast Research, v.13, p. 609-617, 2013. Disponível em: < http://www.ncbi.nlm.nih.gov/pubmed/23826802 >. doi: 10.1111/1567-1364.12062

ZUROFF, T.R.; XIQUES, S.B.; CURTIES, W.R. Consortia-mediated bioprocessing of cellulose to ethanol with a symbiotic Clostridium phytofermentans/yeast co-culture. Biotechnology for Biofuels, v. 6, n.1 p. 59, 2013. Disponível em: < http://www.ncbi.nlm.nih.gov/pubmed/23628342>. doi: 10.1186/1754-6834-6-59. 